\title{
Clinical presentation of orthostatic hypotension in the elderly
}

\author{
G.M. Craig \\ Formerly Consultant Geriatrician, Northampton Health Authority, Northampton, UK
}

\begin{abstract}
Summary: Fifty cases of orthostatic hypotension in the elderly are analysed. Three main modes of presentation were identified: (1) falls or mobility problems; (2) mental confusion or dementia; or (3) predominantly cardiac symptoms. Selected case histories are given to illustrate diagnostic difficulties. Medication was responsible for orthostatic hypotension in $66 \%$ of patients and striking examples of polypharmacy were encountered. However, $34 \%$ of cases were not iatrogenic. Only $14 \%$ of patients had overtly postural symptoms. A high index of suspicion is needed to diagnose orthostatic hypotension in the elderly and the condition is often overlooked. The paper provides useful diagnostic clues for clinicians.
\end{abstract}

\section{Introduction}

Orthostatic hypotension is common in hospital geriatric practice. The condition may present in unusual ways in the elderly and can easily be overlooked. Some cases are a consequence of autonomic failure. Physiological and pathology aspects, and treatment of autonomic failure are quite well covered in the literature. ${ }^{1-5}$ Detailed tests have been devised to locate the precise level of neuronal dysfunction once the diagnosis has been established ${ }^{6}$ and the clinical features have been well described. ${ }^{7}$ Yet patients often endure months of disability before the diagnosis is made.

\section{Case material}

This paper is based on a study of 50 elderly patients. All patients included in the series had an orthostatic fall in systolic blood pressure of $20 \mathrm{mmHg}$ or more. In most cases symptoms were alleviated by measures that increased systolic blood pressure. The majority of patients were under the care of the author and were seen either as hospital in-patients (21) or as outpatients (1) or domiciliary consultations (28) over a 7 year period. Cases were collected sporadically initially and later more systematically. The series was completed with patients remembered and traced by retrospective study of domiciliary consultation notes. For this

Correspondence: G.M. Craig, F.R.C.P., 118 Cedar Road East, Abington, Northampton NN3 2JF, UK. Accepted: 11 April 1994 reason the patients' age is not on record in ten cases. With this proviso the mean age was 80 years ( $n=40$, range 63-97 years). There were $24 \mathrm{men}$ and 26 women in the series.

\section{Clinical presentation}

The presenting features in order of frequency are shown in Table I. The symptoms were obtained from a study of the history as recorded in the case notes or domiciliary notes. No formal protocol or standard questionnaire was employed.

Table I Presenting features in 50 patients with orthostatic hypotension

\begin{tabular}{lcc}
\hline Feature & $\begin{array}{c}\text { Number of } \\
\text { patients }\end{array}$ & Percentage \\
\hline 1. Falls & 32 & 64 \\
2. Poor mobility & 22 & 44 \\
3. Unsteadiness & 19 & 38 \\
4. Confusion & 11 & 22 \\
5. Postural symptoms & 7 & 14 \\
6. Fractures & 6 & 12 \\
7. Dementia & 5 & 10 \\
8. Blackouts & 4 & 8 \\
9. Angina & 3 & 6 \\
10. Reluctance to stand & 3 & 6 \\
11. Pallor, tiredness & 3 & 6 \\
12. Fits & 2 & 4 \\
13. Headache & 1 & 2 \\
14. Asymptomatic & 1 & 2 \\
\hline
\end{tabular}


The presenting features fell into three main groups: (1) falls or mobility problems; (2) mental confusion or dementia; and (3) predominantly cardiac symptoms.

\section{Falls or mobility problems}

This was the commonest mode of presentation. Some patients fell repeatedly, others had poor mobility or were unsteady when walking. One or two had become bedbound. Thirteen suffered falls plus poor mobility and three were reluctant to stand. Six had sustained fractures in falls. Three case histories are given to illustrate the problems.

Case 1 A woman of 70 with chronic lymphatic leukaemia complained of trembling and shaking that prevented her from getting out of bed without help. When standing with support she was giddy and felt a tight band across her head. She was depressed and slept badly. She was taking flupenthixol, levodopa with carbidopa (Sinemet plus), amiloride hydrochloride with hydrochlorothiazide (Moduretic), clonidine hydrochloride, loprazolam daily, aspirin daily and prochlorperazine maleate. Her blood pressure was $140 / 80 \mathrm{mmHg}$ lying and $110 / 80 \mathrm{mmHg}$ standing. There was no good evidence of Parkinson's disease. A diagnosis of iatrogenic orthostatic hypotension and depression was made. Sinemet, flupenthixol, moduretic and Stemetil were stopped and clonidine was gradually withdrawn. Her orthostatic hypotension was cured and she rapidly regained her mobility. Depression was treated with dothiepin.

Case 2 A woman aged 85 years with a fractured neck of femur treated by an Austin Moore prosthesis failed to mobilize after operation and was transferred to a geriatric ward for rehabilitation. She was found to have severe orthostatic hypotension with a blood pressure of $145 / 70 \mathrm{mmHg}$ lying, $95 \mathrm{mmHg}$ systolic standing. With below knee elastic stockings her standing systolic blood pressure rose to $105 \mathrm{mmHg}$ and she started to walk. No treatable cause of orthostatic hypotension was found. She remained incontinent of urine and severely demented and was discharged to a nursing home. Three months later she fell again and sustained another fracture.

\section{Mental confusion or dementia}

Another group of patients presented with mental confusion or overt dementia. The latter is not by definition reversible but undoubtedly poor cerebral perfusion due to orthostatic hypotension can make cerebral function worse. Case 3 illustrates this point.
Case 3 A female aged 80 had a 6 week history of incontinence of urine and faecal soiling with inappropriate defaecation and unsteadiness on her feet. She complained of bad headaches and wavy lines in front of her eyes since starting thioridazine $25 \mathrm{mg}$ three times a day. Her eyesight was poor and her behaviour had become odd. She spent the day sleeping in her chair, no longer attempted to wash or dress herself and was extremely forgetful. She appeared unsteady on standing at times and grabbed her daughter for support. On examination she was mentally confused with an abbreviated mental test score of 0 out of 10 . Her blood pressure was $105 / 70 \mathrm{mmHg}$ sitting, falling to $75 / 60 \mathrm{mmHg}$ after standing for a few minutes. There were no cardiac murmurs and no neurological abnormalities. She was admitted to hospital, thioridazine was withdrawn and faecal impaction and a urinary infection were treated. She regained her continence and mobility but confusion due to senile dementia persisted. Her blood pressure rose to 150/ $90 \mathrm{mmHg}$ with no orthostatic drop.

\section{Predominantly cardiac symptoms}

A third group of patients had predominantly cardiac symptoms. Some had underlying cardiac disease and were receiving treatment for cardiac failure. Three cases are described to illustrate this group of patients. One had a low cardiac output due to left atrial thrombus, one had iatrogenic hypotension due to treatment of cardiac failure complicated by depression and one had iatrogenic hypotension due to inappropriate medication given for oesophageal pain that had been misdiagnosed as angina.

Case 4 A female aged 72 was admitted with intractable leg ulcers for which she had been receiving stanozolol. She was treated with antibiotics and stanozolol was discontinued. After 2 months the leg ulcers had healed but the patient started to deteriorate, tiring visibly on walking across the room. Her pulse became faint on walking and she had mild orthostatic hypotension, blood pressure $120 \mathrm{mmHg}$ systolic sitting, $100 \mathrm{mmHg}$ systolic standing. An electrocardiogram showed atrial fibrillation. She developed a left femoral embolus and died. The postmortem showed a ball valve thrombus in the left atrium.

Case 5 A man aged 75 with intractable cardiac failure due to ischaemic heart disease was treated with hydralazine hydrochloride $25 \mathrm{mg}$ twice a day, bumetanide $3 \mathrm{mg}$ daily and captopril $50 \mathrm{mg}$ twice a day. He was started on mianserin hydrochloride $30 \mathrm{mg}$ nocte for depression, and shortly afterwards became dyspnoeic and so weak that he could not move in bed. Blood pressure was $100 / 60 \mathrm{mmHg}$ 
systolic lying and unrecordable on standing. The pulse was 80 sinus rhythm, the jugular venous pressure was raised and he was in urinary retention. Although he was in severe congestive cardiac failure, it was felt that some symptoms were due to orthostatic hypotension which may have been partly iatrogenic. Mianserin and hydralazine were stopped, he was started on metolazone and was catheterized. Four weeks later he could walk with slight dyspnoea, had minimal oedema, felt much better and was catheter free.

Case 6 A man aged 80 with Parkinson's disease was short of breath and had 'angina' requiring excessive amounts of nitrate. He complained of poor locomotion and falls, retrosternal pain at night and swollen ankles. His wife felt that he was addicted to a nitrolingual spray. On referral he was taking triamterene $50 \mathrm{mg}$ with hydrochlorothiazide $25 \mathrm{mg}$ (Dyazide), propranolol, nifedipine levodopa with carbidopa, Sinemet, benzhexol, methixene hydrochloride, indomethacin slow release, one daily, plus glyceryl trinitrate (GTN) and nitrolingual spray. The patient had discontinued GTN and his wife had confiscated the nitrolingual spray a week before the domiciliary consultation. As a result he was said to be more alert and his ankles were less swollen.

On examination he had a slight Parkinsonian tremor. The blood pressure was $110 / 60 \mathrm{mmHg}$ sitting, falling to $80 / 50 \mathrm{mmHg}$ on standing. There was no evidence of cardiac failure and abdominal examination was normal. An electrocardiogram was normal. His falls were attributed to orthostatic hypotension and additional gastric pathology was suspected. Barium studies showed an incarcerated hiatus hernia. His medication was gradually reduced until he was taking only the antiParkinson's medication. His general mobility improved and his blood pressure rose to 120 / $60 \mathrm{mmHg}$ standing. Nocturnal retrosternal pain was attributed to reflux and responded to an $\mathrm{H}_{2}$ receptor antagonist.

\section{Iatrogenic orthostatic hypotension}

Medication was implicated in orthostatic hypotension in $\mathbf{4 0}$ out of 50 patients and was thought to be primarily responsible for orthostatic hypotension in $33(66 \%)$. The medication taken is shown in Table II. Where patients were taking a combined diuretic, such as triamterene plus a thiazide, this was counted as two diuretics for purposes of analysis. The mean number of drugs taken per patient was 1.98 (range $0-9$ ). The commonest drug prescribed was a diuretic (in $56 \%$ of patients) closely followed by benzodiazepines $(26 \%)$, antidepressants $(24 \%)$ and anti-parkinsonian drugs
$(22 \%)$. Of 11 patients on treatment for Parkinson's disease, six were taking L-dopa, two selegiline, two anti-cholinergic drugs and one bromocriptine. The commonest phenothiazine used was prochlorperazine which is frequently prescribed for nonspecific giddiness. The commonest anti-depressant implicated was amitriptylene (in 11 patients).

\section{Non-iatrogenic orthostatic hypotension}

Ten patients were on no medication, and 17 had known pathology that may have been implicated in their orthostatic hypotension (Table III). Altogether, $34 \%$ of patients had orthostatic hypotension that was not iatrogenic in origin.

\section{Discussion}

The elderly are at particular risk of developing autonomic failure ${ }^{2,3}$ and orthostatic hypotension, which is frequently multifactorial and often iatrogenic. Orthostatic hypotension can be particularly troublesome in Parkinson's disease ${ }^{8}$ as a result of autonomic dysfunction, medication or an unrelated condition - in one study $19 \%$ of patients were affected. ${ }^{9}$

The classical presentation of orthostatio hypotension is dizziness or fainting on standing erect. Although opinions vary ${ }^{1}$ the usual clinica definition of orthostatic hypotension is a fall of $20 \mathrm{mmHg}$ or more in systolic blood pressure on standing. The incidence of this is $15 \%$ in people aged $65-75$ years and $25 \%$ in those aged over $75 .{ }^{10}$ This degree of postural drop may be asymp-

Table II Medication taken by 50 patients with orthostatic hypotension

\begin{tabular}{lcc}
\hline Medication & $\begin{array}{c}\text { Number of } \\
\text { patients }\end{array}$ & Percentage \\
\hline 1. Diuretic(s) & 28 & 56 \\
2. Benzodiazepine & 13 & 26 \\
3. Anti-depressant & 12 & 24 \\
4. Anti-parkinsonian & 11 & 22 \\
$\quad$ therapy & & \\
5. Phenothiazines & 9 & 18 \\
6. Beta blockers & 6 & 12 \\
7. Hydralazine & 5 & 10 \\
8. Calcium antagonist & 4 & 8 \\
9. Nitrates & 3 & 6 \\
10. Methyldopa & 3 & 6 \\
11. Angiotensin converting & 2 & 4 \\
$\quad$ enzyme & & \\
12. Alpha blocker & 1 & 2 \\
13. Clonidine & 1 & 2 \\
14. No medication & 10 & 20 \\
\hline
\end{tabular}


Table III Pathology associated with orthostatic hypotension, unrelated to medication

\begin{tabular}{lc}
\hline Pathology & $\begin{array}{c}\text { Number of } \\
\text { patients }\end{array}$ \\
\hline $\begin{array}{l}\text { Neurological } \\
\text { Senile dementia }\end{array}$ & 4 \\
$\begin{array}{l}\text { Cerebrovascular disease } \\
\text { Peripheral neuritis }\end{array}$ & 2 \\
$\quad \begin{array}{l}\text { Shy-Drager syndrome } \\
\text { Carcinoma } \\
\quad \text { Larynx, prostate or lung }\end{array}$ & 2 \\
$\begin{array}{l}\text { Cardiac } \\
\text { Ball valve thrombus in } \\
\quad \text { left atrium }\end{array}$ & 4 \\
$\quad$ Aortic stenosis & 1 \\
$\begin{array}{l}\text { Miscellaneous } \\
\text { Lobar pneumonia with } \\
\text { zinc deficiency }\end{array}$ & 1 \\
$\quad \begin{array}{l}\text { Peripheral vascular } \\
\text { disease and septicaemia }\end{array}$ & 1 \\
Total & $17(34 \%)$ \\
\hline
\end{tabular}

tomatic, but if the fall in systolic blood pressure is more substantial or the standing systolic blood pressure is $110 \mathrm{mmHg}$ or less, symptoms may develop. Orthostatic hypotension may not become clinically apparent until symptoms occur, but asymptomatic orthostatic hypotension may, in my opinion, cause insidious damage to organs such as the kidneys and brain which may become clinically significant.

Unfortunately it is not unusual for doctors at all levels to fail to diagnose a classical case of orthostatic hypotension. Since postural symptoms are uncommon in the elderly (Table I) diagnostic errors can occur only too easily. Reduced cerebral perfusion can cause epileptiform convulsions leading to a mistaken diagnosis of epilepsy. Transient visual disturbance suggesting occipital lobe ischaemia can mimic a transient ischaemic attack or cerebrovascular disease. Reduced coronary perfusion with dyspnoea and chest pain may masquerade as ischaemic heart disease and this may have been a factor in case 6. Orthostatic syncope in a patient with ischaemic heart disease may be mistaken for a Stokes Adams attack. Many old people with orthostatic hypotension are unable to give a good history and doctors need to be alert to the small clues that may suggest the diagnosis, which is readily established at the bedside. Where patients are so incapacitated that they cannot stand, measurement of the lying and sitting blood pressure may confirm the diagnosis. A finger on the pulse may demonstrate that it becomes weak or imperceptible on standing.
Patients may present with fits, faints, falls or fractures, reluctance to walk, mental confusion or unexplained blackouts. They may become bedbound or chairbound for no apparent reason. Some decline to participate in physiotherapy or any activity that requires adoption of an upright posture. They may be dismissed as hysterical or poorly motivated. Others get agitated or belligerent when asked to stand up, and may refuse. They may try to co-operate only to sit down hurriedly. They may become pale and vasoconstricted on standing. Patients who do not volunteer any symptoms will often admit to dizziness or unsteadiness if asked how they feel when they stand up.

Although postural symptoms were uncommon in the present series, in one Swedish study $40 \%$ of women and $30 \%$ of men aged 75 had symptoms such as unsteadiness, impending blackout, vertigo and lightheadedness. ${ }^{11}$ Although some Swedish subjects had investigations such as cerebral blood flow, electroencephalography and echo encephalography, blood pressure was not mentioned once in the paper. This underlines the fact that a diagnosis of orthostatic hypotension is frequently not considered in the elderly.

Drug-induced orthostatic hypotension is a major problem in the elderly and should be suspected in any patient taking two or more drugs with hypotensive potential. Case 6 is a particularly striking example of polypharmacy. A significant association has been demonstrated between falls in the elderly and the use of hypnotic and antidepressant drugs. ${ }^{12,13}$ In psychogeriatric patients systolic orthostatic hypotension, disease classification, and type and number of drugs taken contribute independently to dizziness and falls. ${ }^{12}$ Patients on a tricyclic anti-depressant with any other hypotension-producing drug have a significantly increased risk of falling. ${ }^{12}$ Once iatrogenic orthostatic hypotension has been diagnosed it may be relatively easy to treat by a reduction in medication. Where orthostatic hypotension cannot be attributed to medication, further investigation is required to exclude other treatable causes of secondary orthostatic hypotension.

Falls were a major problem in $64 \%$ of our patients and fear of falling contributed to immobility in others. In one study of ataxia in old people with falls, more than $50 \%$ of those in whom sway was recorded had orthostatic hypotension and a number of patients with orthostatic hypotension could not stand long enough to have their degree of ataxia recorded. ${ }^{14}$ Orthostatic hypotension should be considered and taken seriously in any patient with unexplained falls.

Orthostatic hypotension can be caused by a low cardiac output of varied aetiology but a ball valve thrombus in the left atrium as in case 4 must be 
exceedingly rare. Orthostatic hypotension may reduce coronary perfusion in the erect posture and cause myocardial infarction ${ }^{15}$ or incapacitating symptoms. Congestive cardiac failure is said not to cause orthostatic hypotension as such patients tolerate head-up tilt well. ${ }^{2}$ However, iatrogenic orthostatic hypotension can occur in patients with congestive cardiac failure and medication may be a factor as demonstrated by case 5. Attempts to reduce medication can prove difficult and must be carefully judged. Diuretics can cause orthostatic hypotension by fluid or sodium depletion; one study suggesting that the risk is not great is of doubtful value as patients who could not stand

\section{References}

1. Thomas, J.E., Schirger, A., Fealey, R.D. \& Sheps, S.G. Orthostatic hypotension. Proc Staff Meet Mayo Clinic 1981, 56: $117-135$.

2. Bannister, R. \& Mathias, C.J. Introduction and classification of autonomic disorders. In: Bannister, R. \& Mathias, C.J. (eds.) Autonomic Failure. Oxford University Press, Oxford, 1992, pp. 1-11.

3. Johnson, R.H. Ageing and the automatic nervous system. In Bannister, R. \& Mathias, C.J. (eds.) Autonomic Failure. Oxford University Press, Oxford, 1992, pp. 882-903.

4. Watson, R.D.S. Treating postural hypotension. $\mathrm{Br}$ Med $J$ 1987, 294: 390-391.

5. Shy, G.M. \& Drager, G.A. A neurological syndrome associated with orthostatic hypotension. Arch Neurol 1960, 2 $511-527$.

6. Polinsky, R.J. Neuropharmacological investigation of automatic failure. In: Bannister, R. \& Mathias, C.J. (eds.) Autonomic Failure. Oxford University Press, Oxford, 1992, pp. 334-358.

7. Bannister, R. \& Mathias, C.J. Clinical features and investigation of the primary autonomic failure syndromes. In: Bannister, R. \& Mathias, C.J. (eds.) Autonomic Failure. Oxford University Press, Oxford, 1992, pp. 531-547.

8. Gross, M., Bannister, R. \& Goodwin-Austen, R. Orthostatic hypotension in Parkinson's disease. Lancet 1972, 1: 174-176. were excluded. ${ }^{16}$ The risk of hypotension when treating depression in elderly patients with cardiovascular disease has been known for many years. ${ }^{15}$

Measurement of lying and standing blood pressure should be a routine part of the clinical examination of all patients presenting with falls, all who are at risk from medication, and all who have symptoms or signs such as those listed in Table I. If clinicians had a higher index of suspicion, more patients with treatable orthostatic hypotension would be discovered and much misery could be alleviated.

9. Wilson, J.A. \& Smith, R.G. The prevalance and aetiology of long term L-Dopa side effects in elderly parkinsonian patients. Age Ageing 1989, 18: 11-16.

10. Weatherall, D.J., Ledingham, J.G.G. \& Warrell, D.A. (eds.) Oxford Textbook of Medicine, Vol. 2. Oxford University Press, Oxford, 1983, 25.8.

11. Sixt, E. \& Landahl, S. Postural disturbances in a 75 year old population: prevalence and functional consequence. Age Ageing 1987, 16: 393-398.

12. Davie, J.W., Blumenthal, M.D. \& Robinson-Hawkins, S. A model of risk of falling for psychogeriatric patients. Arch Gen Psychiatry 1981, 38: 463-467.

13. Blake, A.J., Morgan, K., Bendell, M.J. et al. Falls by elderl people at home: prevalence and associated factors. Ağ Ageing 1988, 17: 365-372.

14. Sharma, J.C. \& MacLennan, W. Causes of ataxia in patient attending a falls laboratory. Age Ageing 1988, 17: 94-102.

15. Muller, O.F., Goodman, N. \& Bellet, S. The hypotensive effect of imipramine hydrochloride in patients with cardiovascular disease. Clin Pharmacol Ther 1961, 2: 300-307.

16. Myers, N.G., Kearns, P.M., Kennedy, D.S. \& Fisher, R.H Postural hypotension and diuretic therapy in the elderly CMA J 1978, 119: 581-585. 